\title{
A Compact Kapton-based Inkjet Printed Multiband Antenna for Flexible Wireless Devices
}

\author{
Sana Ahmed, Farooq A. Tahir, A. Shamim, Hammad M. Cheema
}

\begin{abstract}
A low cost inkjet printed multiband antenna envisioned for integration into flexible and conformal mobile devices is presented. The antenna structure contains a novel triangular iterative design with coplanar waveguide (CPW) feed, printed on a Kapton polyimide-based flexible substrate with dimensions of $70 \times 70 \times 0.11 \mathrm{~mm}^{3}$. The antenna covers four wide frequency bands with measured impedance bandwidths of $54.4 \%, 14 \%, 23.5 \%$ and $17.2 \%$, centered at $1.2,2.0,2.6$ and 3.4 GHz, respectively, thus, enabling it to cover GSM 900, GPS, UMTS, WLAN, ISM, Bluetooth, LTE 2300/ 2500 and WiMAX standards. The antenna has omnidirectional radiation pattern with a maximum gain of $2.1 \mathrm{dBi}$. To characterize the flexibility of the antenna, the fabricated prototype is tested in convex and concave bent configurations for radii of $78 \mathrm{~mm}$ and $59 \mathrm{~mm}$. The overall performance remains unaffected, except a minor shift of $20 \mathrm{MHz}$ and $60 \mathrm{MHz}$ in S11, for concave bending at both radii. The compact, lightweight and conformal design as well as multiband performance in bent configurations, proves the suitability of the antenna for future electronic devices.
\end{abstract}

Index Terms-Flexible antennas, multiband antennas, inkjet printing, Kapton, wireless applications.

\section{INTRODUCTION}

$\mathrm{R}$ ecent years have witnessed growing research in the field of flexible electronics. Enabling components such as transistors, inductors, capacitors and antennas are increasingly being reported [1] that address the future requirements of lightweight, low cost and flexible electronic devices compatible with unusual substrates such as paper, textiles and plastics. In addition to the trends of flexible and bendable devices, multiband support is required in many cases. For instance, today's typical mobile devices support $2 \mathrm{G}, 3 \mathrm{G}$, and 4G-LTE as well as WLAN and GPS standards. For such devices, antennas that are flexible as well as multiband are unavoidable. At the same time, the antenna, among all other components on flexible substrates, is the most prone to performance degradation because of its radiation characteristics getting severely affected by substrate deformation. It is therefore critical to study and analyze the flexibility aspect of the antenna.

Manuscript received Dec. 30, 2014.

Sana Ahmed, Farooq A. Tahir and Hammad M. Cheema are with the School of Electrical Engineering and Computer Science (SEECS), National University of Sciences and Technology, Islamabad, Pakistan (emails: 12mseesahmed, farooq.tahir, hammad.cheema, @ seecs.edu.pk).

A. Shamim is with the Department of Computer, Electrical and Mathematical Sciences and Engineering (CEMSE), King Abdullah University of Sciences and Technology (KAUST), Thuwal, KSA (email: atif.shamim@kaust.edu.sa).
To address these requirements, antennas have been attempted on paper and other polymer substrates using techniques such as screen printing and inkjet printing. The latter of these is becoming popular as a low cost and fast prototyping fabrication process. Being an additive process, the design is directly transferred on to the substrate without the need of expensive masks and material wastage [2].

Typically the multiband antennas used in mobile devices are planar monopole or planar inverted-F antenna (PIFA) structures [3-5]. However, they are implemented on rigid FR-4 or similar substrates and are not compatible with conformal requirements. At the same time, antennas designed on flexible substrates such as papers, liquid crystal polymers (LCP) and PET films are reported in [6-8], but they are not multiband. In [9-10], two different multiband antennas on paper substrate are presented but without flexibility analysis. A performance analysis in bent and deformed configuration of antennas have been done in [11-12] but these antennas cover only one or two frequency bands.

In this paper, a novel and conformal multiband antenna is presented using inkjet printing process on Kapton substrate. A generalized iterative design approach is adopted to achieve the multiband response. Effects of adding each antenna radiator are studied and analyzed. A comparative analysis of antenna parameters between straight and different bent configurations is also included.

\section{ANTENNA DESIGN \& WORKING MECHANISM}

The design of the proposed planar monopole antenna is shown in Fig. 1. Focusing on design goals of impedance matching at the selected bands and extracting maximum gain for each band, the antenna consists of iterative triangular radiators, fed by a coplanar waveguide (CPW) with circularshaped ground plane. The radiators are designed to operate at four specific frequencies as a proof-of-concept only. In order to cover other desired communication bands, the size of each radiator and spacing between consecutive radiators can be easily adjusted, making it a flexible and scalable design. CPW feed is chosen for its simplicity and ease of fabrication in a roll-to-roll production process as the radiator and the ground plane are printed on the same side of the substrate [13]. The curved shape of the CPW ground is carefully designed and optimized to adjust the resonance frequencies and operating bands of the antenna. For flexibility, the antenna is designed on a Kapton polyimide-based substrate with a dielectric constant $\left(\varepsilon_{\mathrm{r}}\right)$ of 3.5 , loss tangent $(\delta)$ of 0.002 and compact size of $70 \times 70 \mathrm{~mm}^{2}$ with substrate height of $0.11 \mathrm{~mm}$. The detailed 


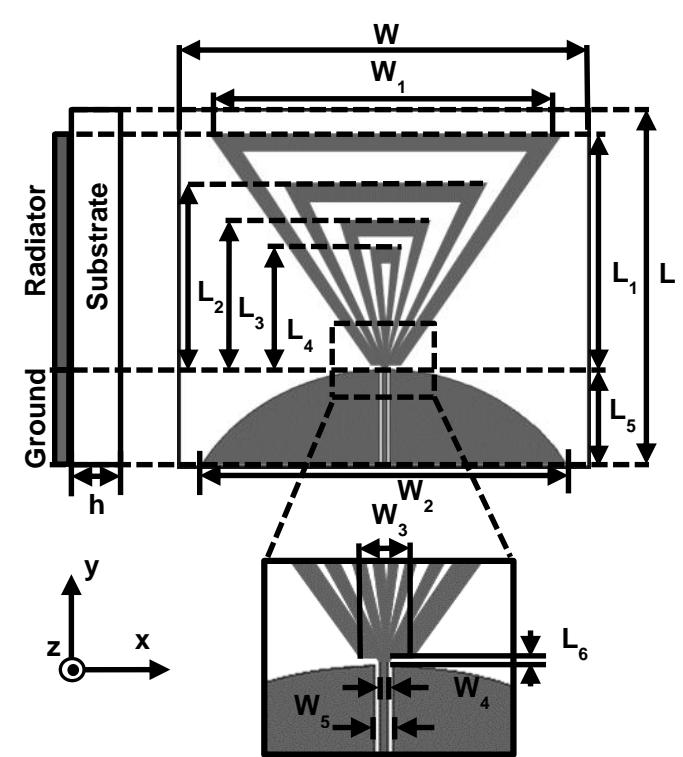

Fig. 1. Layout of the proposed antenna $\left(\mathrm{L}=70 \mathrm{~mm}, \mathrm{~L}_{1}=44.8 \mathrm{~mm}\right.$, $\mathrm{L}_{2}=34.8 \mathrm{~mm}, \mathrm{~L}_{3}=27.8, \mathrm{~L}_{4}=23.5 \mathrm{~mm}, \mathrm{~L}_{5}=20 \mathrm{~mm}, \mathrm{~L}_{6}=0.4 \mathrm{~mm}, \mathrm{~W}=70 \mathrm{~mm}$, $\mathrm{W}_{1}=60 \mathrm{~mm}, \mathrm{~W}_{2}=67.7 \mathrm{~mm}, \mathrm{~W}_{3}=4.4 \mathrm{~mm}, \mathrm{~W}_{4}=0.73 \mathrm{~mm}, \mathrm{~W}_{5}=1.43 \mathrm{~mm}$, $\mathrm{h}=0.11 \mathrm{~mm})$

dimensions of the proposed antenna are shown in Fig.1.

The iterative design procedure is illustrated in Fig. $2(\mathrm{a}-\mathrm{d})$ and the simulated $\mathrm{S}_{11}$ for various iterations is also shown in Fig. 2. In the first step, the antenna contains one CPW-fed radiator that radiates at 1.1 and $2.6 \mathrm{GHz}$ with $S_{11}<-10 \mathrm{~dB}$. In the second step, another radiator is added inside the first one shifting it's resonance from $1.1 \mathrm{GHz}$ to $1.05 \mathrm{GHz}$. At the same time, two more resonances at 2.3 and $3.4 \mathrm{GHz}$ are generated because of mutual coupling between the two radiators. Similarly, the addition of a third and fourth radiator provides resonances at 1.41 and $2.1 \mathrm{GHz}$, respectively, whereas the first two resonances (at 1.1 and $2.6 \mathrm{GHz}$ ) are improved at the same time. The overall return loss in Fig. 2 shows that four wide frequency bands covered by final proposed antenna are $0.88-$ $1.5 \mathrm{GHz}, 1.93-2.2 \mathrm{GHz}, 2.31-2.96 \mathrm{GHz}$ and $3.11-3.58$ $\mathrm{GHz}$.

The performance mechanism of the multiband antenna can also be understood through the analysis of its surface current distribution at the resonating frequencies. The current distribution is shown in Fig. 3 (a - e). Fig. 3 (a) shows that at $1.05 \mathrm{GHz}$, current is concentrated at first resonator whereas at $1.41 \mathrm{GHz}$, second resonator has more current concentration as depicted in Fig. 3 (b). Similarly, Fig. 3 (c) shows that at 2.1 $\mathrm{GHz}$, only third radiator is active whereas at $2.6 \mathrm{GHz}$, both second and third resonators are radiating and finally at 3.3 $\mathrm{GHz}$, the current is more concentrated on the fourth resonator.

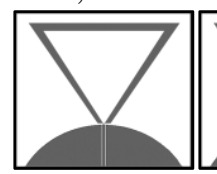

(a)

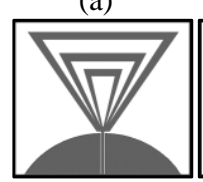

(c)

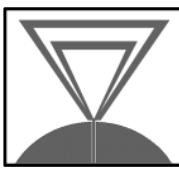

(b)



(d)

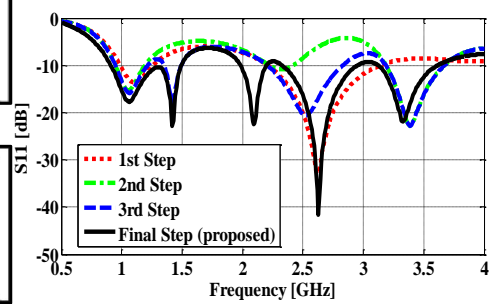

Fig. 2. Design stages of proposed antenna with corresponding S11 (a) 1st Step (b) 2nd Step (c) 3rd Step (d) Final Step (proposed)

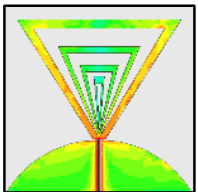

(a)

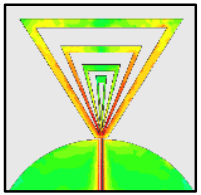

(b)

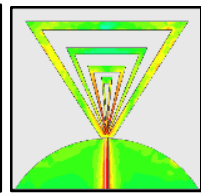

(c)

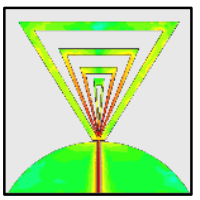

(d)



(e)

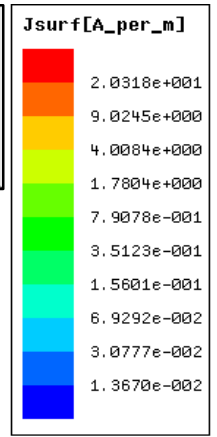

Fig. 3. Simulated current distribution at (a) 1.05 (b) 1.41 (c) 2.1 (d) 2.6 and (e) $3.3 \mathrm{GHz}$

\section{FABRICATION AND MEASURED RESULTS}

The antenna is inkjet-printed using Dimatix DMP-2831 printer and UT Dots silver nano-particle ink. Owing to the smooth surface of Kapton substrate, the nano-particle drop spacing and number of layers are carefully chosen to obtain accurate dimensions as well as good conductivity. An optimized drop spacing of $30 \mu \mathrm{m}$ and 5 conductive layers on top of the each other are used. After printing, the antenna is heat sintered at $120^{\circ} \mathrm{C}$ for 10 minutes. The conductivity thus achieved is approximately $6 e^{6} \mathrm{~S} / \mathrm{m}$. An SMA connector is mounted using conductive silver epoxy. The antenna is tested in normal as well as in bent conditions using Satimo StarLab anechoic chamber. A prototype of fabricated antenna on Kapton substrate is shown in Fig. 4.
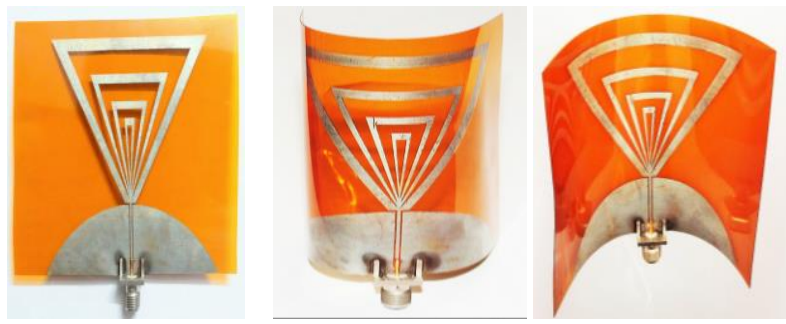

Fig. 4. Fabricated antenna prototype in various positions

The simulated and measured $S_{11}$ is shown in Fig. 5 showing good agreement. The simulated and measured impedance bandwidths for the tetra-bands are shown in Table I. The first band has $54.4 \%$ bandwidth and can cover GSM 900, GPS L2, L3 and L5 bands whereas the second band has $14 \%$ bandwidth and can cover UMTS bands. The bandwidth of the third and fourth band is $25.3 \%$ and $17.2 \%$ respectively, supporting the WLAN, ISM/Bluetooth, LTE 2300/2500 and WiMAX frequency bands.

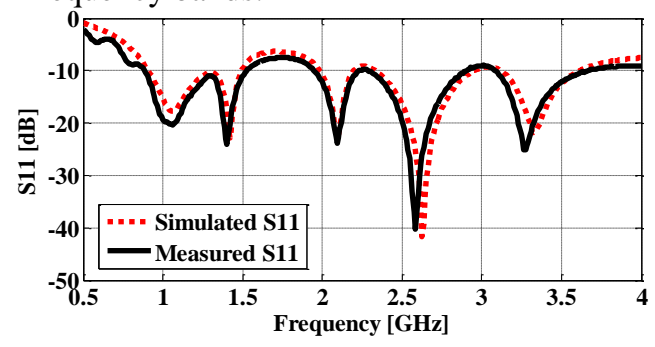

Fig. 5. Simulated and measured S11 of antenna 
TABLE I

\begin{tabular}{|c|c|c|}
\hline \multicolumn{3}{|c|}{ MEASURED BANDWIDTH AND FREQUENCY BANDS COVERED BY ANTENNA } \\
$\begin{array}{c}\text { Band } \\
\text { No. }\end{array}$ & $\begin{array}{c}\text { Measured } \\
\text { bandwidth }\end{array}$ & Covered commercial bands \\
\hline 1. & $\begin{array}{c}0.87-1.52 \mathrm{GHz} \\
(54.4 \%)\end{array}$ & $\begin{array}{c}\text { GSM 900 (880-960 MHz), GPS L5, L2 } \\
\& \text { L3 }(1176.45 \mathrm{MHz}, 1227.60 \mathrm{MHz} \& \\
1381.05 \mathrm{MHz})\end{array}$ \\
\hline 2. & $\begin{array}{c}1.93-2.22 \mathrm{GHz} \\
(14 \%)\end{array}$ & UMTS (1920-2170 MHz) \\
\hline 3. & $\begin{array}{c}2.29-2.90 \mathrm{GHz} \\
(23.5 \%)\end{array}$ & $\begin{array}{c}\text { WLAN (2400-2480 MHz), ISM \& } \\
\text { Bluetooth (2400-2480 MHz), LTE 2300 } \\
(2305-2400 \mathrm{MHz}), \mathrm{LTE} 2500(2500- \\
2690 \mathrm{MHz})\end{array}$ \\
\hline 4. & $\begin{array}{c}3.07-3.65 \mathrm{GHz} \\
(17.2 \%)\end{array}$ & WiMAX (3400-3600 MHz) \\
\hline
\end{tabular}

The simulated and measured E-plane and $\mathrm{H}$ - plane radiation patterns of the antenna at $0.9,2.0$ and $2.5 \mathrm{GHz}$, are shown in Fig. 6 (a) - (c). It can be observed that E- plane and H-plane results, at all frequencies show monopole like and omnidirectional radiation patterns, respectively, making it compatible for the mobile communication applications. The simulated and measured realized gain along with simulated peak efficiency is compared in Table II. The measured peak gain is $-1.2 \mathrm{dBi}$ for the lowest frequency band, $0.6 \mathrm{dBi}$ for 2 $\mathrm{GHz}$ band and $2.1 \mathrm{dBi}$ for $2.5 \mathrm{GHz}$ band. The maximum difference between the simulated and measured gain is $\pm 1 \mathrm{~dB}$.
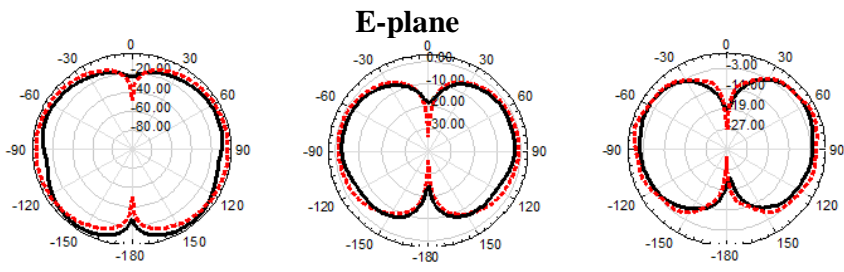

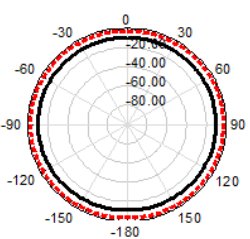

(a)

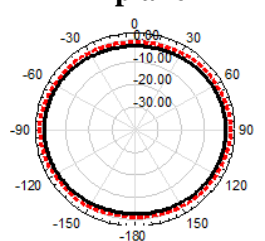

(b)

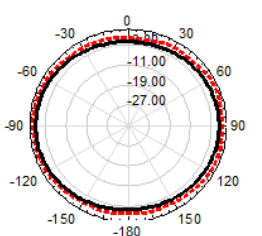

(c)
Simulated Radiation Pattern

Measured Radiation Pattern

Fig. 6. Simulated and measured radiation patterns at (a) $0.9 \mathrm{GHz}$ (b) $2 \mathrm{GHz}$ (c) $2.5 \mathrm{GHz}$

TABLE II

COMPARISON BETWEEN THE SIMULATED AND MEASURED GAIN

\begin{tabular}{|c|c|c|c|c|}
\hline $\begin{array}{c}\text { Band } \\
\text { No. }\end{array}$ & $\begin{array}{c}\text { Bandwidth } \\
(\mathbf{G H z})\end{array}$ & $\begin{array}{c}\text { Simulated } \\
\text { Gain }\end{array}$ & $\begin{array}{c}\text { Measured } \\
\text { Gain }\end{array}$ & $\begin{array}{c}\text { Simulated } \\
\text { Peak Efficiency }\end{array}$ \\
\hline 1. & $0.8-1.0$ & $-1 \mathrm{dBi}$ & $-1.2 \mathrm{dBi}$ & $67 \%$ \\
\hline 2. & $1.4-2.2$ & $1.3 \mathrm{dBi}$ & $0.6 \mathrm{dBi}$ & $82 \%$ \\
\hline 3. & $2.5-2.7$ & $2.7 \mathrm{dBi}$ & $2.1 \mathrm{dBi}$ & $81 \%$ \\
\hline
\end{tabular}

\section{BENDING ANALYSIS}

The potential use of the presented antenna in bendable and flexible devices requires its characterization in various bent configurations. For this purpose, the antenna is bent in convex and concave directions by attaching it on a foam with different radii. Its return loss and radiation performance is then measured in each case. Considering the typical bending capabilities for future flexible wireless devices, cylindrical radii of $R_{1}=78 \mathrm{~mm}$ and $R_{2}=59 \mathrm{~mm}$ for bending analysis in both convex and concave configurations are chosen. The antenna in bent form for $\mathrm{R}_{1}=78 \mathrm{~mm}$ in both configurations is shown in Fig. 7. (a)

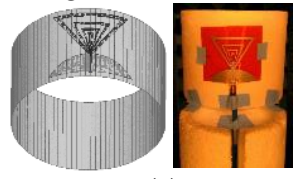

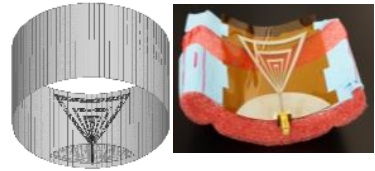

(b)
Fig. 7. Antenna bending (a) convex configuration (b) concave configuration

Fig. 8 depicts the simulated and measured return loss comparison of the bent antenna at different radii in both convex and concave configurations with the unbent antenna. In the former configuration, no significant degradation is observed, apart from the slight shift in resonance frequency of the first band $(0.87-1.52 \mathrm{GHz})$. This happens primarily due to the outer most radiator, which gets most effected by the convex bending. In case of concave bending, a maximum shift of $20-60 \mathrm{MHz}$ is observed towards the lower-end in all the frequency bands. The wide impedance bandwidth of the antenna still retains the matching at the desired operating frequencies.

The radiation patterns in the bent configurations are also measured in detail and a small shift is observed between them as shown in Fig. 9 and 10. The detailed comparison of the peak gain in bent and unbent configurations is also shown in Table III. In case of the convex bending, maximum increase of $0.3 \mathrm{~dB}$ and $0.4 \mathrm{~dB}$ in gain is observed in the frequency band at $2 \mathrm{GHz}$ for $78 \mathrm{~mm}$ and $59 \mathrm{~mm}$ respectively. Similarly, for concave bending, maximum increase of $0.3 \mathrm{~dB}$ is observed in the $2 \mathrm{GHz}$ frequency band, for both radii. This change in gain is observed due to slight increase in the directivity when antenna is bent. Furthermore, after repeated testing of antenna under different bending conditions, no major degradation in the radiation characteristics is observed. The excellent repeatability and the durability qualify the presented design for future flexible devices.

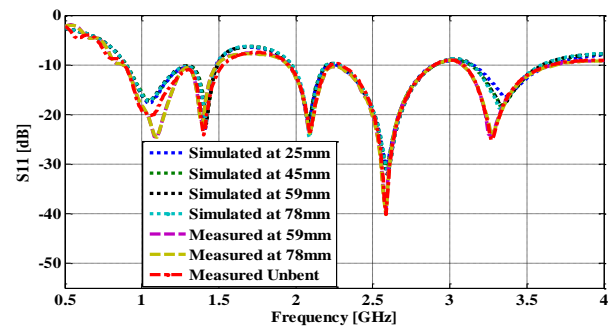

(a)

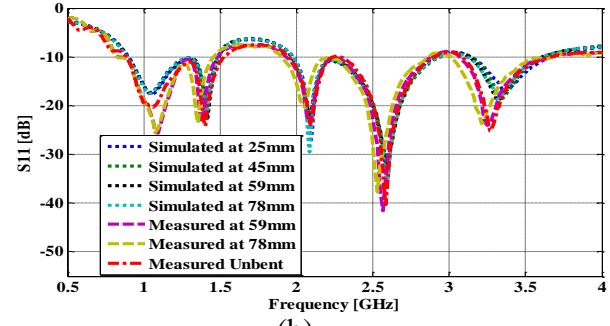

(b)

Fig. 8. Simulated and measured S11 of the antenna when unbent and bent on foam of different radii in (a) convex (b) concave configurations 

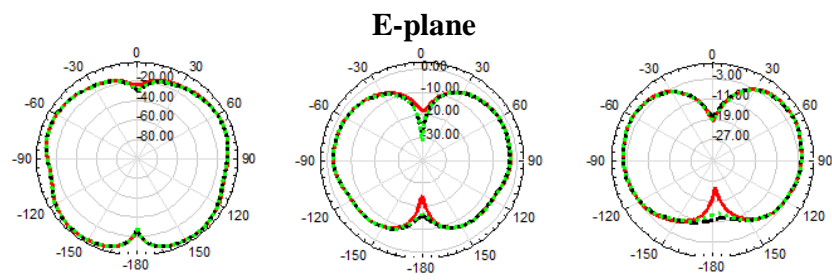

H-plane


(b)

(a)
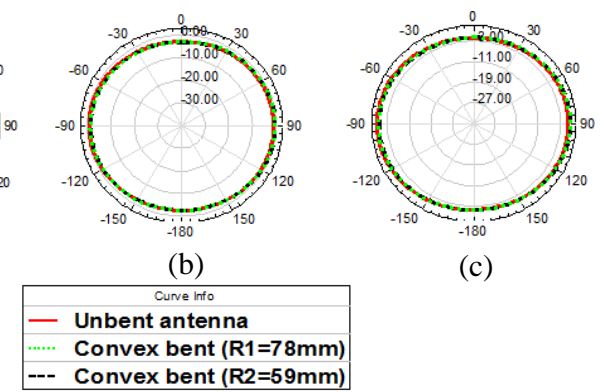

(c)

Fig. 9. Comparison between the measured radiation patterns of the unbent and convex bent antenna at (a) $0.9 \mathrm{GHz}$ (b) $2 \mathrm{GHz}$ (c) $2.5 \mathrm{GHz}$


H-plane



(a)

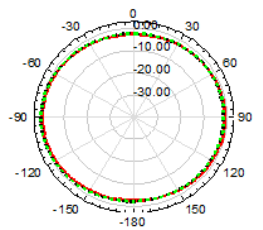

(b)

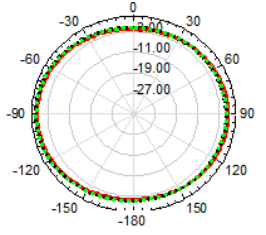

(c)

\section{- Unbent antenna \\ Concave bent $(\mathrm{R} 1=\mathbf{7 8 \mathrm { mm }})$ \\ --- Concave bent $(\mathbf{R} 2=59 \mathrm{~mm})$}

Fig. 10. Comparison between the measured radiation patterns of the unbent and concave bent antenna at (a) $0.9 \mathrm{GHz}$ (b) $2 \mathrm{GHz}$ (c) $2.5 \mathrm{GHz}$

TABLE III

GAIN COMPARISON BETWEEN UNBENT AND BENT ANTENNA CONFIGURATIONS

\begin{tabular}{|c|c|c|c|}
\hline \multicolumn{4}{|c|}{ Convex Configuration } \\
\hline Band No. & Unbent antenna & $\begin{array}{c}\text { Bent at } \mathbf{R}_{\mathbf{1}}= \\
\mathbf{7 8 m m}\end{array}$ & $\begin{array}{c}\text { Bent at } \mathbf{R}_{\mathbf{2}}= \\
\mathbf{5 9 m m}\end{array}$ \\
\hline 1. & $-1.2 \mathrm{dBi}$ & $-1.2 \mathrm{dBi}$ & $-1.2 \mathrm{dBi}$ \\
\hline 2. & $0.6 \mathrm{dBi}$ & $0.9 \mathrm{dBi}$ & $1.0 \mathrm{dBi}$ \\
\hline 3. & $2.1 \mathrm{dBi}$ & $2.3 \mathrm{dBi}$ & $2.5 \mathrm{dBi}$ \\
\hline \multicolumn{4}{|c|}{ Concave Configuration } \\
\hline Band No. & Unbent antenna & $\begin{array}{c}\text { Bent at } \mathbf{R}_{\mathbf{1}}= \\
\mathbf{7 8 m m}\end{array}$ & $\begin{array}{c}\text { Bent at } \mathbf{R}_{\mathbf{2}}= \\
\mathbf{5 9 m m}\end{array}$ \\
\hline 1. & $-1.2 \mathrm{dBi}$ & $-1.1 \mathrm{dBi}$ & $-1.1 \mathrm{dBi}$ \\
\hline 2. & $0.6 \mathrm{dBi}$ & $0.9 \mathrm{dBi}$ & $0.9 \mathrm{dBi}$ \\
\hline 3. & $2.1 \mathrm{dBi}$ & $2.1 \mathrm{dBi}$ & $2.2 \mathrm{dBi}$ \\
\hline
\end{tabular}

\section{CONCLUSION}

A novel design of inkjet-printed flexible multiband antenna is presented with detailed simulated and measured results. The multiple iterations within the triangular monopole design helps to achieve the multiband operation with wide bandwidths

without increasing the antenna form factor. The antenna resonates at $1.2,2.0,2.6$ and $3.4 \mathrm{GHz}$ with measured bandwidth of $54.4 \%, 14 \%, 23.5 \%$ and $17.2 \%$ respectively and can cover GSM 900, GPS, UMTS, WLAN, ISM, Bluetooth, LTE 2300/ 2500 and WiMAX frequency bands. A maximum resonance frequency shift of $3 \%$ is observed in concave bending, while no significant change is observed in convex bending. The measured results reveal omnidirectional radiation patterns with -1.2 to $2.5 \mathrm{dBi}$ gain, when tested in unbent as well as bent conditions. As a result, the proposed flexible, compact, lightweight and robust design along with good radiation characteristics suggest that the antenna is suitable for various wireless applications for future conformal and flexible electronic devices.

\section{ACKNOWLEDGMENT}

The authors would like to thank Fahad Farooqui and Shuai Yang of IMPACT Lab, KAUST, KSA for fabrication and measurement assistance.

\section{REFERENCES}

[1] J. Hu, "Overview of flexible electronics from ITRI's viewpoint," Proc. VLSI Test Symp., pp.84 -84 2010.

[2] L. Yang, A. Rida, R. Vyas and M. M. Tentzeris, "RFID tag and RF structures on a paper substrate using inkjet-printing technology," IEEE Trans. Microw. Theory Tech., vol. 55, no. 12, pp.2894 -2901, Dec. 2007.

[3] N. Bayatmaku, P. Lotfi, M. Azarmanesh, and S. Soltani, "Design of simple multi-band patch antenna for mobile communication applications using new E-shape fractal," IEEE Antennas Wireless Propag. Lett., vol. 99, p. 1, 2011.

[4] Anguera, J., I. Sanz, J. Mumbru, and C. Puente, "Multiband handset antenna with a parallel excitation of PIFA and slot radiators," IEEE Trans. Antennas Propag., Vol. 58, No. 2, 348-356, Feb. 2010.

[5] Asghar, A. M., M. Malick, M. Karlsson, and A. Hussain, "A multiwideband planar monopole antenna for $4 \mathrm{G}$ devices," Microwave Opt. Technol. Lett., vol. 55, No. 3, 589-593, March 2013.

[6] S. Nikolaou, M. M. Tentzeris and J. Papapolymerou, "Study of a conformal UWB elliptical monopole antenna on flexible organic substrate mounted on cylindrical surfaces," Proc. 18th IEEE PIMRC, pp.1 -4 2007.

[7] H. F. Abutarboush and A. Shamim, "Conformal and green electronics:A wideband Inkjet printed antenna on paper substrate," Proc.7th EuCAP, pp.3099-3102 2013

[8] H. K. Yoon, W. S. Kang, Y. J. Yoon, and C. H. Lee, "A flexible UWB antenna attachable to various kinds of materials," in Proceedings of the IEEE International Conference on Ultra-Wideband (ICUWB '07), pp. 204-209, Sept. 2007.

[9] H. F. Abutarboush, A. Shamim, "Paper-Based Inkjet-Printed Tri-Band U-Slot Monopole Antenna for Wireless Applications," IEEE Antennas Wireless Propag. Lett., vol.11, pp.1234-1237, 2012.

[10] H. F. Abutarboush, A. Shamim, "Wide frequency independently controlled dual-band inkjet-printed antenna," IET Microwaves, Antennas \& Propagtion, vol. 8, Issue 1, p. 52 - 56, Jan. 2014.

[11] D. E. Anagnostou, A. A. Gheethan, A. K. Amert, and K. W. Whites, "A direct-write printed antenna on paper-based organic substrate for flexible displays and WLAN applications," J. Display Technol., vol. 6, no. 11, pp. 558-564, Nov. 2010.

[12] H.R. Khaleel, H.M. Al-Rizzo and D.G. Rucker, "Compact PolyimideBased Antennas for Flexible Displays," J. Display Technol., vol. 8, no 2, pp. 91-97, Feb. 2012.

[13] H. R. Khaleel, H. M. Al-Rizzo, and A. I. Abbosh, "Design, fabrication, and testing of flexible antennas," in Advancement in Microstrip Antennas With Recent Applications, A. Kishk, Ed., InTech, Vienna, Austria, 2013. 